\title{
Predicted habitat shifts of Pacific top predators in a changing climate
}

\author{
Elliott L. Hazen ${ }^{1,2 \star}$, Salvador Jorgensen ${ }^{3}$, Ryan R. Rykaczewski ${ }^{4}$, Steven J. Bograd ${ }^{1}$, David G. Foley ${ }^{1,2}$, \\ Ian D. Jonsen ${ }^{5}$, Scott A. Shaffer ${ }^{6}$, John P. Dunne ${ }^{7}$, Daniel P. Costa ${ }^{8}$, Larry B. Crowder ${ }^{9,10}$ \\ and Barbara A. Block9
}

To manage marine ecosystems proactively, it is important to identify species at risk and habitats critical for conservation. Climate change scenarios have predicted an average sea surface temperature (SST) rise of $1-6^{\circ} \mathrm{C}$ by 2100 (refs 1, 2), which could affect the distribution and habitat of many marine species. Here we examine top predator distribution and diversity in the light of climate change using a database of 4,300 electronic tags deployed on 23 marine species from the Tagging of Pacific Predators project, and output from a global climate model to 2100. On the basis of models of observed species distribution as a function of SST, chlorophyll $a$ and bathymetry, we project changes in species-specific core habitat and basin-scale patterns of biodiversity. We predict up to a $35 \%$ change in core habitat for some species, significant differences in rates and patterns of habitat change across guilds, and a substantial northward displacement of biodiversity across the North Pacific. For already stressed species, increased migration times and loss of pelagic habitat could exacerbate population declines or inhibit recovery. The impending effects of climate change stress the urgency of adaptively managing ecosystems facing multiple threats.

Many top predators in marine ecosystems are in decline globally owing to overfishing, bycatch and other indirect anthropogenic threats including habitat loss and changes in prey availability ${ }^{3}$. Large ocean predators can provide top-down control of food webs and when these species are removed or displaced, resulting trophic cascades can alter the stability of marine ecosystems ${ }^{4,5}$. Furthermore, changes in habitat may have multiple economic effects on coastal communities through reduced availability of ecosystem services such as fisheries landings and ecotourism.

Climate change has resulted in shifts in species distributions in both terrestrial and marine systems ${ }^{6,7}$. Climate change ranks as one of the greatest anthropogenic threats to terrestrial biodiversity ${ }^{8}$, although less is known in marine systems. Models assessed by the Intergovernmental Panel on Climate Change estimate that global ocean surface temperatures will rise between 1 and $6^{\circ} \mathrm{C}$ by 2100 (refs 1,2). Both acute and long-term exposure to warmer waters could impact species distributions through direct physiological and indirect ecological pathways ${ }^{9,10}$. However, the rates and intensity of climate impacts will not be uniform across the world's oceans; thus,

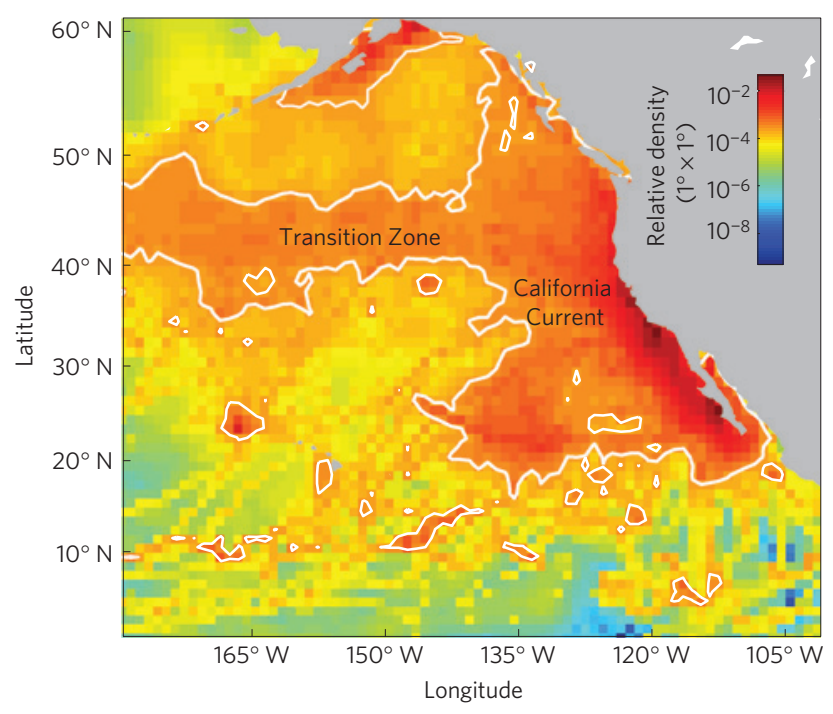

Figure 1 | Density of top predators within the eastern North Pacific. Densities of the time-weighted and species-normalized position estimates of all tagged individuals were summed within $1^{\circ} \times 1^{\circ}$ grid cells. The two densest biological hotspots are labelled; the white contour represents the top $25 \%$ of density values from 2001 to 2009 . Modified from Fig. 4 of ref. 11 .

understanding spatial patterns of change is critical for identifying ecosystems most at risk.

Comprehensive analyses of the effects of climate change inherently require an interdisciplinary approach. Remotely sensed environmental and animal distribution data can be combined in a habitat-modelling framework to both assess and predict how animals interact with their environment. The Tagging of Pacific Predators (TOPP) programme resulted in an unprecedented biologging data set by deploying over 4,300 electronic tags on 23 species from 2000 to 2009 in the North Pacific (Fig. 1). Pelagic predator hotspots in the northeast Pacific have been identified by quantifying the links between predator distribution and environmental features ${ }^{11}$. Here we combine species-specific habitat models from the TOPP data set with climate change projections ${ }^{12,13}$ of SST and chlorophyll $a$ to

${ }^{1}$ NOAA Southwest Fisheries Science Center, Environmental Research Division, 1352 Lighthouse Avenue, Pacific Grove, California 93950, USA, ${ }^{2}$ Joint Institute for Marine and Atmospheric Research, University of Hawaii at Manoa, 1000 Pope Road, Marine Science Building 312, Honolulu, Hawaii 96822, USA, ${ }^{3}$ Monterey Bay Aquarium, Monterey, California 93940, USA, ${ }^{4}$ Princeton University, Princeton, New Jersey 08544, USA, ${ }^{5}$ Dalhousie University, Department of Biology, Halifax, Nova Scotia B3H 4J1, Canada, ${ }^{6}$ San Jose State University, Department of Biological Sciences, San Jose, California 95192, USA, ${ }^{7}$ NOAA Geophysical Fluid Dynamics Laboratory, Princeton, New Jersey 08540, USA, ${ }^{8}$ University of California, Santa Cruz, Department of Ecology \& Evolutionary Biology, Long Marine Laboratory, Santa Cruz, California 95060, USA, 9 Stanford University, Biology Department, Hopkins Marine Station, Pacific Grove, California 93950, USA, ${ }^{10}$ Center for Ocean Solutions, Monterey, California 93940, USA. *e-mail: Elliott.hazen@noaa.gov. 

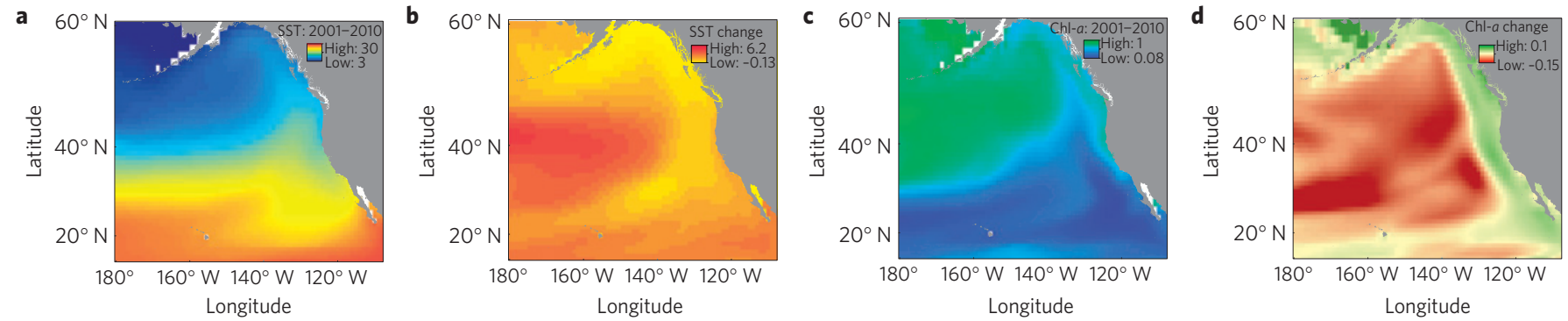

Figure 2 | Modelled SST and chlorophyll-a values and predicted changes. a-d, Yearly climatological maps of modelled SST and chlorophyll- $a$ (Chl- $a$ ) patterns from 2001 to 2010 (a,c) and changes in SST and chlorophyll a from the first and last 20 years of 2001 to 2100 (b,d) in the North Pacific.
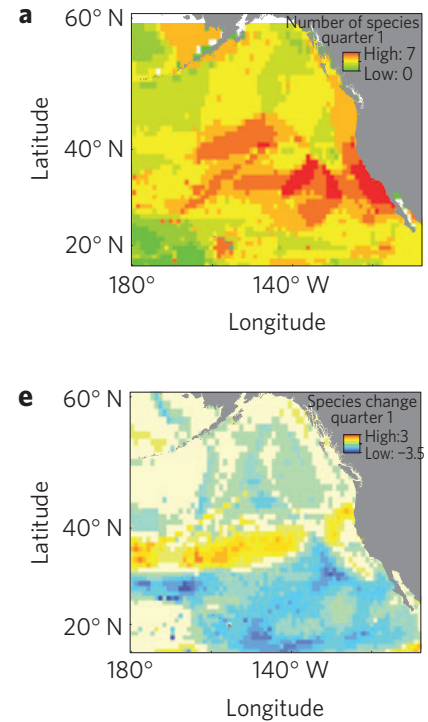
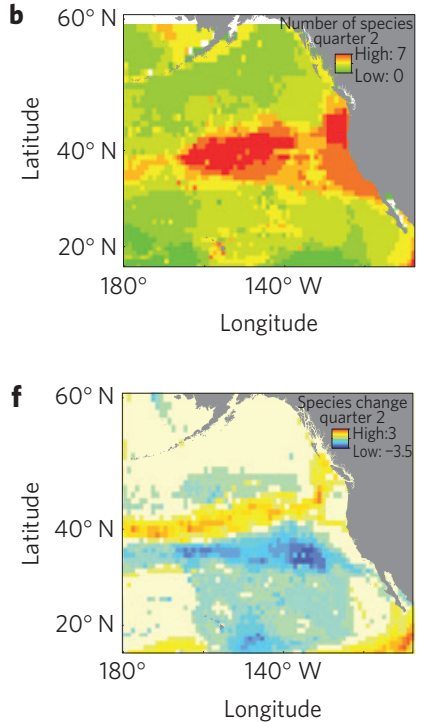
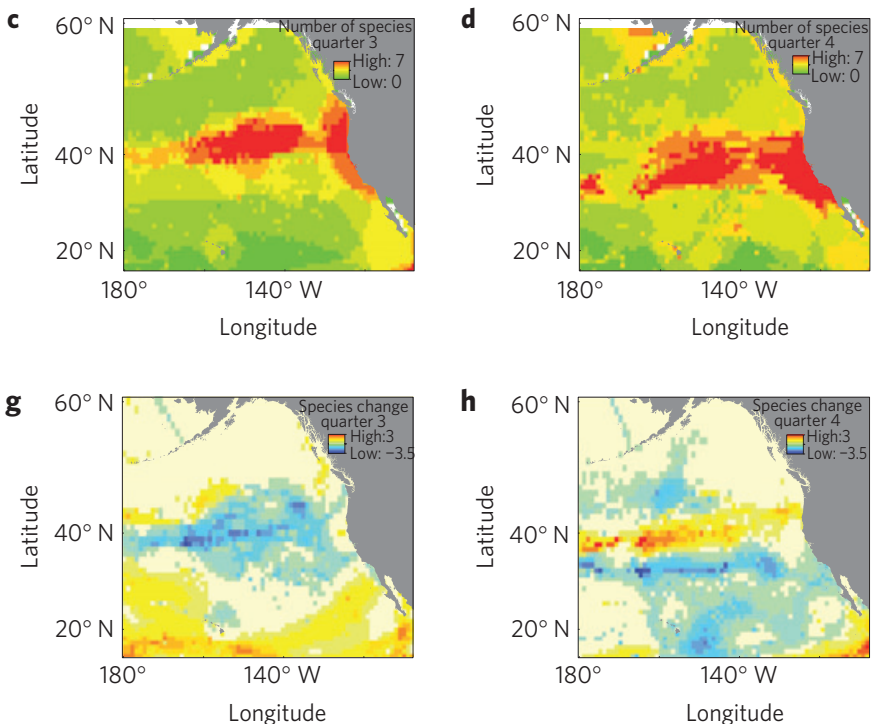

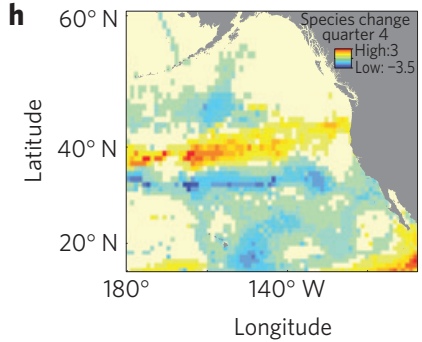

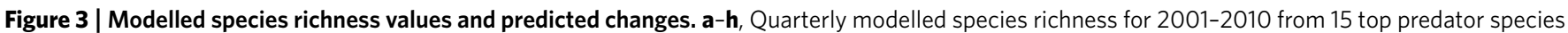
(a-d) and predicted changes in species richness over the next century (2001-2020 compared with 2081-2100) (e-h).

predict rates and spatial patterns of change in top predator diversity, and species most at risk of losing pelagic habitat under climate change. This scenario-driven approach can be used to identify areas of stability as well as change in biodiversity across management boundaries, providing data essential to strategically and proactively manage dynamic marine ecosystems.

\section{Results}

The Geophysical Fluid Dynamics Laboratory coupled model for scenario A2 predicted SST changes as high as $5^{\circ} \mathrm{C}$ and chlorophyll- $a$ changes up to $\pm 0.2 \mathrm{mg} \mathrm{l}^{-1}$ between 2001 and 2100 in the northeast Pacific Ocean (Fig. 2). The largest temperature changes occurred in the North Pacific Transition Zone (NPTZ) whereas the upwellingdriven California Current Large Marine Ecosystem (CCLME) showed minimal change $\left(<1^{\circ} \mathrm{C}\right)$. These trends were accompanied by a decrease in chlorophyll $a$ in the central North Pacific and an increase in chlorophyll $a$ along the coastal margins. Spatial patterns were similar under scenario A1B but had a lower magnitude of change (not shown).

We found varied relationships among core habitat and oceanographic variables across species. The mean deviance explained by the reduced generalized additive models was $20 \%$ for all species $($ minimum $=9 \%$ and maximum $=44 \%$; Supplementary Table S1). The seabird guild targeted high-chlorophyll- $a$ waters $\left(>0.2 \mathrm{mgl}^{-1}\right)$, the tuna guild targeted moderate SSTs $\left(\sim 15-25^{\circ} \mathrm{C}\right)$, whereas the shark guild targeted both higher chlorophyll $a$ and moderate SST, highlighting the diversity of habitats used by top predators (Supplementary Fig. S1).
Predictive models of core habitat showed primary biodiversity hotspots in the CCLME and in the NPTZ $\left(\sim 43^{\circ} \mathrm{N}\right.$ latitude) with these regions serving as core habitat area for seven of the fifteen species during all seasons. These predicted results from 2001 to 2010 were similar to the previously published TOPP observations, validating our approach ${ }^{11}$ (Fig. 1). Patterns in biodiversity showed a northward shift in core habitat as the NPTZ moved north in all seasons but the summer (Fig. 3). Richness decreased by up to $20 \%$ in the NPTZ and the warmer subtropical gyre as temperatures warmed in the winter, spring and autumn. Diversity patterns remained near constant in the California Current with the core habitat area of all species increasing $2 \%$ over the course of the twenty-first century.

There was high variability in predicted changes in core habitat area, $\pm 35 \%$ across all species (Fig. 4 and Supplementary Fig. S3). Seabirds and tuna guilds had the greatest gains in potential core habitat, whereas the shark guild showed the greatest decline, and the marine mammal and turtle guilds had slight decreases. Rates of change were often nonlinear, with some species losing habitat quicker than others (Supplementary Fig. S3). Of all species, sooty shearwaters were predicted to have the greatest gain in habitat whereas mako sharks were predicted to lose the most habitat (Fig. 4f). Sooty shearwaters, blackfooted albatross and loggerhead turtles had the greatest variance in predicted habitat change.

\section{Discussion}

We used spatial models of top predator species distributions in concert with global climate models to project changes in North Pacific biodiversity hotspots and to identify functional groups 
a

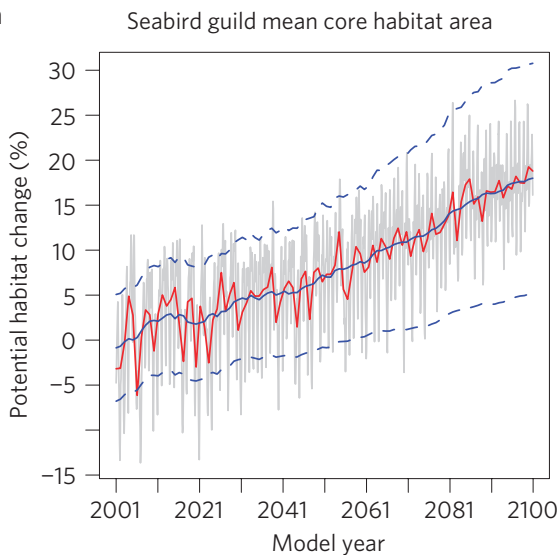

C

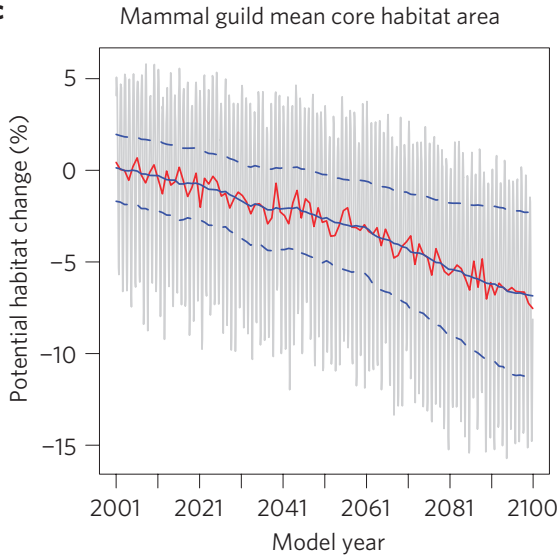

$\mathbf{e}$

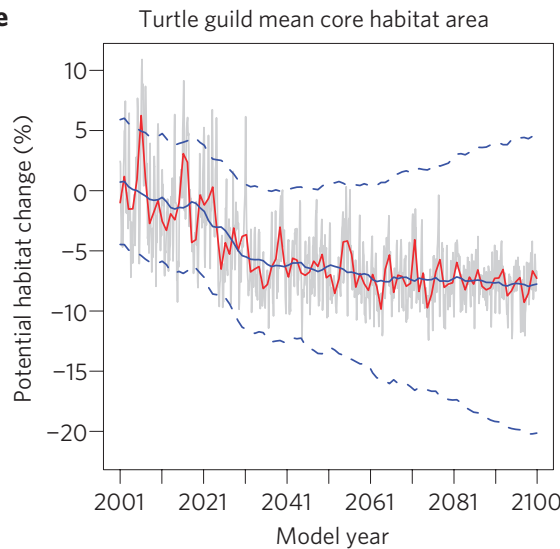

b

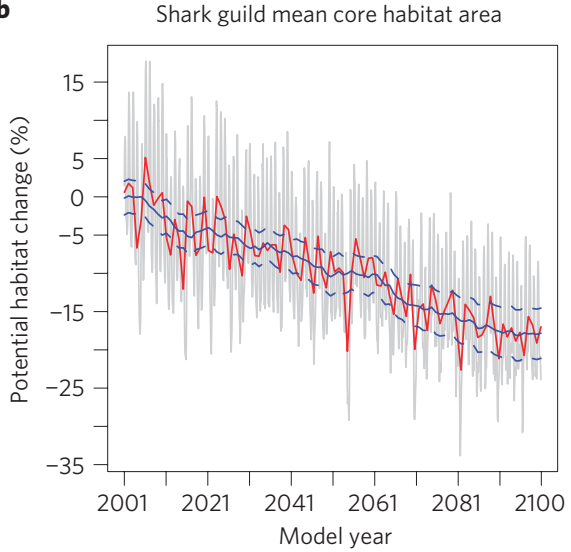

d

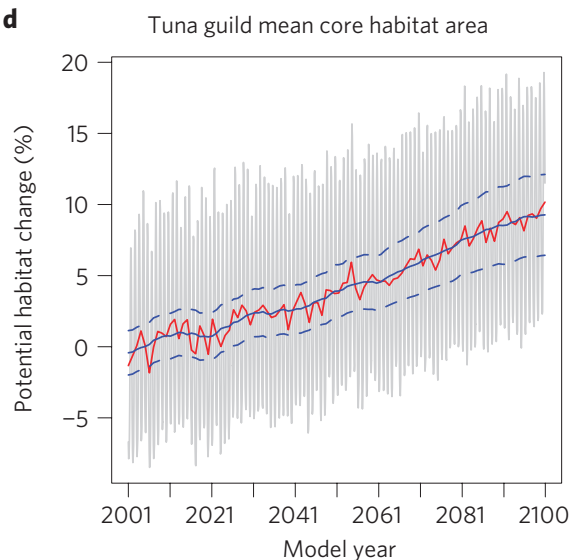

$\mathbf{f}$

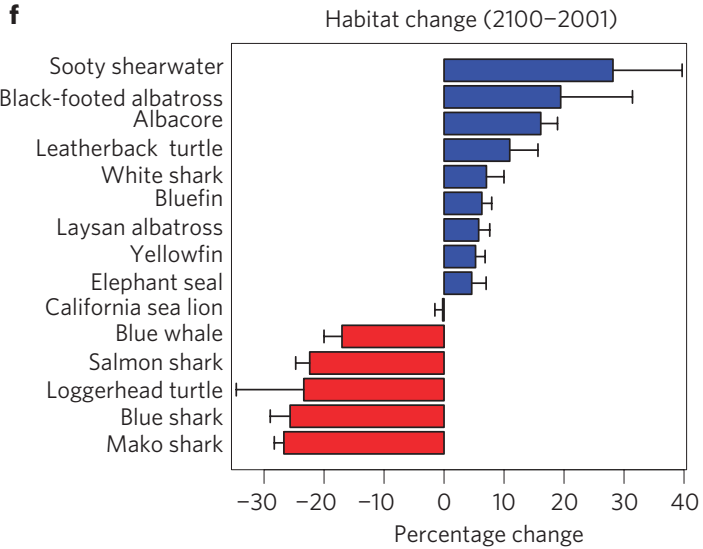

Figure 4 | Predicted changes in top predator core habitat by guild. a-e, Top predator core habitat area by guild from 2000 to 2100 shown as monthly (grey), yearly (red) and 5-year filtered (blue) time series with 1 standard deviation marked by dashed lines. f, Total predicted mean habitat change from 2001 to 2100 for each of the 15 top predator species with 1 standard deviation error bars.

most at risk. The climate model output showed a northward migration of up to $1,000 \mathrm{~km}$ of the NPTZ, contraction of the subarctic gyre and expansion of the oligotrophic subtropical gyre ${ }^{14}$ (Fig. 2). These physical changes will drive a substantial northward shift in biodiversity across the North Pacific for species with both commercial and conservation value. Modelled ecosystem changes predict increased species overlap and a potential for niche compression under the Intergovernmental Panel on Climate Change A2 scenario (Fig. 3).

We found significant differences in habitat change across guilds resulting in species-specific winners and losers. The shark guild showed the greatest risk of pelagic habitat loss with 3 out of 4 species showing declines (Fig. 4 and Supplementary Fig. S3). Tuna species gained core habitat, potentially owing to their higher use of the CCLME. Marine mammals declined in potential habitat, largely driven by blue whales, whereas seabirds had the greatest increase in potential habitat. Species with specialized diets (for example, blue whales and leatherbacks) may have less capacity for adaptation and therefore will be more susceptible to environmental changes than prey-switching generalists (for example, tuna and seabirds) ${ }^{10,15}$. Similarly, species with broader thermal tolerances may be more successful than those with limited thermal tolerances ${ }^{6}$. In addition, increases in fisheries catch may exacerbate climate change effects on both fished species and predator populations ${ }^{15-17}$.

Our predicted climate change impacts on threatened or endangered species could have varied effects on population recovery 
efforts. Marine top predators can have high phenotypic plasticity and adaptive capability that may reduce climate change impacts, whereas mismatches between predators and prey due to climatic shifts could enhance climate change impacts. Among turtles, loggerheads showed a decline in core habitat, whereas leatherbacks foraging in the California Current had a slight increase in potential habitat projected. However, nesting beach development and skewed sex ratios from warmer nesting temperatures may negate projected foraging habitat gains for endangered leatherbacks ${ }^{18}$. Seabirds had the greatest predicted gains in pelagic habitat, but changes in wind regimes and resultant migration corridors may mean potential habitat is inaccessible ${ }^{19}$. Furthermore, loss of seabird nesting habitat on low-lying atolls due to sea-level rise may lead to population extinctions ${ }^{20}$. Blue whales showed a decrease in predicted core habitat, which could limit their post-whaling recovery ${ }^{21}$, whereas elephant seals were predicted to have an increase in available habitat in the North Pacific. Central place foragers such as pinnipeds and seabirds have additional constraints when compared with migratory fish, sharks and whales, as hotspots such as the NPTZ may move further from existing colonies, adding increased energetic cost and decreasing reproductive success, particularly during sensitive life-history stages ${ }^{19}$ (Fig. 3).

Waters within the west coast US exclusive economic zone were predicted to increase in chlorophyll $a$ and also remain high biodiversity hotspots in the future (Figs 2 and 3). As offshore habitat decreases or becomes less accessible, there may be increased use in the CCLME leading to greater competition among top predators, but also a higher risk of anthropogenic impacts such as shipping traffic and fisheries bycatch ${ }^{22}$. In the Pacific, oxygen minimum zones are both expanding and shoaling ${ }^{23}$. A shallower oxygen minimum zone could reduce vertical habitat for fishes with high oxygen demand while concentrating prey for air-breathing mammals, turtles and seabirds. In a spatially explicit framework, maps of changes in ecosystem services, habitat preferences and trophic interactions could serve as the foundation for reserve design and marine spatial planning in a changing ocean ${ }^{24}$.

The complexity and broad-scale effects of climate change make it difficult to determine changes or distributional shifts a priori. Marine organisms, particularly pelagic predators, offer added difficulty in prediction because they are highly migratory, spend a large portion of their lives below the surface of the ocean and have complex physiological specializations ${ }^{11}$. However, the marine realm is predicted to face marked changes by 2040 (ref. 25), so we must use our best science to identify individual species and biodiversity hotspots most at risk and to implement management and intervention methods using a precautionary approach $^{26}$. Habitat models based on animal movement data and real-time oceanography open the possibility of dynamic marine protected areas that are oriented to transient oceanic features (for example, fronts, eddies and upwelling zones) rather than those fixed on stationary habitats (for example, reefs and seamounts). Policy prescriptions for pelagic marine reserves are being actively debated now both inside exclusive economic zones of nations and in the open sea ${ }^{27}$. Management strategies and reserves need to be based not only on present biodiversity distributions and migration corridors but also on their persistence in the future.

To truly understand the multiple stressors faced by a species, an ecosystem-based approached is needed. Integrated ecosystem models of trophic dynamics and energy flow could be used to look at changes in forage species and the effects on predators ${ }^{28}$ in addition to predicted changes in fisheries landings ${ }^{17}$. These modelling approaches are not without limitation, as a $1^{\circ}$ grid-size model does not resolve fine-scale oceanic or ecological processes that interact on the scale of individuals ${ }^{13}$. Results of this and similar approaches ${ }^{29,30}$ are critical to initially assess risk and vulnerability of species to climate change so that managers can proactively target those species most at risk. Climate change is a broad-scale and directional process and we must plan accordingly to ensure our healthy and functioning ecosystems remain intact, and recovery efforts are appropriately targeted and successful.

\section{Methods}

Fifteen of the twenty-three TOPP species had sample sizes sufficient to use in our analysis (resulting in 1791 individual tracks, see Supplementary Information). We used a Bayesian state-space model to account for variable levels of observation error among tag types and to produce regular daily location positions including estimates of uncertainty ${ }^{11}$. Tracks were normalized by deployment duration to account for tag biases ${ }^{11}$. We modelled the density of each predator species in $1^{\circ} \times 1^{\circ}$ grid cells as additive, non-parametric functions of oceanographic variables, bathymetry and season. Satellite-derived fields of chlorophyll $a$, SST, sea surface height anomaly and variance, wind stress curl and bathymetry were used to create time series of monthly values within each grid cell from 2000 to 2009. We fitted generalized additive models for species densities within each grid cell in a full model (all environmental variables) and subsequently in a reduced model for chlorophyll $a$, SST, latitude, longitude and bathymetry.

We used output from a prototype Earth system model (ESM2.1) developed at the Geophysical Fluid Dynamics Laboratory of the National Oceanic and Atmospheric Administration (NOAA). ESM2.1 is a dynamic atmosphere-ocean general circulation model ${ }^{12}$ coupled to a marine biogeochemistry model that allows us to project spatial patterns in SST and chlorophyll $a$ (refs 13,14). Whereas most climate change models use SST alone, we examined monthly changes in both SST and chlorophyll $a$ from 2001 to 2100, which informed our generalized additive model predictions for each species. ESM2.1 was not initialized to observations; thus, decadal variability is represented statistically but the phase of variability will not match observed phases.

We modelled changes in the 15 species distributions from 2001 to 2100 and used 120 bootstrapped runs to examine process variability. Core habitat was defined as the upper 25th percentile of habitat use based on SST, chlorophyll $a$ and bathymetry thresholds from model fits (see Supplementary Information). Spatial changes in patterns of biodiversity were examined using species richness indices by summing the number of species with core habitat in each grid cell. Mean richness from 2001 to 2020 was compared with richness from 2081 to 2100 to examine the climate change signal independent of decadal variability.

Received 12 December 2011; accepted 14 August 2012; published online 23 September 2012

\section{References}

1. Rosenzweig, C. et al. Attributing physical and biological impacts to anthropogenic climate change. Nature 453, 353-357 (2008).

2. IPCC Climate Change 2007: Synthesis Report (eds Core Writing Team, Pachauri, R. K. \& Reisinger, A.) (IPCC, 2007); available at www.ipcc.ch/pdf/assessment-report/ar4/syr/ar4_syr.pdf.

3. Worm, B. \& Tittensor, D.P. Range contraction in large pelagic predators. Proc. Natl Acad. Sci. USA 108, 11942-11947 (2011).

4. Myers, R. A. et al. Cascading effects of the loss of apex predatory sharks from a coastal ocean. Science 315, 1846-1850 (2007).

5. Estes, J. A. et al. Trophic downgrading of planet earth. Science 333, 301-306 (2011)

6. Parmesan, C. Ecological and evolutionary responses to recent climate change Ann. Rev. Ecol. Evol. Syst. 37, 637-669 (2006).

7. Burrows, M. T. et al. The pace of shifting climate in marine and terrestrial ecosystems. Science 334, 652-655 (2011).

8. Thomas, C. et al. Extinction risk from climate change. Nature 427, 145-148 (2004).

9. Pörtner, H. O. \& Knust, R. Climate change affects marine fishes through the oxygen limitation of thermal tolerance. Science 315, 95-97 (2007).

10. O'Connor, M. I. et al. Warming and resource availability shift metabolism of a marine food web. PLoS Bio. 7, e1000178 (2009).

11. Block, B. A. et al. Tracking apex marine predator movements in a dynamic ocean. Nature 475, 86-90 (2011).

12. Delworth, T. L. et al. GFDL's CM2 global coupled climate models. Part I: Formulation and simulation characteristics. J. Clim. 19, 643-674 (2006).

13. Stock, C. A. et al. On the use of IPCC-class models to assess the impact of climate on living marine resources. Prog. Ocean. 88, 1-27 (2010).

14. Polovina, J. J. et al. Projected expansion of the subtropical biome and contraction of the temperate and equatorial upwelling biomes in the North Pacific under global warming. ICES J. Mar. Sci. 68, 986-995 (2011).

15. Harley, C. D. G. Climate change, keystone predation, and biodiversity loss. Science 334, 1124-1127 (2011).

16. Hsieh, C. H. et al. Fishing elevates variability in the abundance of exploited species. Nature 443, 859-862 (2006).

17. Cheung, W. W. L. et al. Large-scale redistribution of maximum fisheries catch potential in the global ocean under climate change. Glob. Change Biol. 16, 24-35 (2010). 
18. Hamann, M. et al. Global research priorities for sea turtles: informing management and conservation in the 21st century. End. Spec. Res. 11, 245-269 (2010).

19. Weimerskirch, H. et al. Changes in wind pattern alter albatross distribution and life-history traits. Science 335, 211-214 (2012).

20. Baker, J. D., Littnan, C. L. \& Johnston, D. W. Potential effects of sea level rise on the terrestrial habitats of endangered and endemic megafauna in the Northwestern Hawaiian Islands. End. Spec. Res. 3, 21-30 (2007).

21. Calambokidis, J., Barlow, J. \& Ford, J. Insights into the population structure of blue whales in the Eastern North Pacific from recent sightings and photographic identification. Mar. Mam. Sci. 25, 816-832 (2009).

22. Zydelis, R. et al. Dynamic habitat models: Using telemetry data to project fisheries bycatch. Proc. R. Soc. B 278, 3191-3200 (2011).

23. Stramma, L. et al. Ocean oxygen minima expansions and their biological impacts. Deep-Sea Res. I 57, 587-595 (2010).

24. Lubchenco, J. \& Sutley, N. Proposed US policy for ocean, coast, and Great Lakes Stewardship. Science 328, 1485-1486 (2010).

25. Brierley, A. \& Kingsford, M. Impacts of climate change on marine organisms and ecosystems. Curr. Biol. 19, R602-R614 (2009).

26. Dawson, T. P. et al. Beyond predictions: Biodiversity conservation in a changing climate. Science 332, 53-58 (2011).

27. Game, et al. Pelagic protected areas: The missing dimension in ocean conservation. TREE 24, 360-369 (2009).

28. Lehodey, P. et al. Preliminary forecasts of Pacific bigeye tuna population trends under the A2 IPCC scenario. Prog. Ocean. 86, 302-315 (2010).

29. Tittensor, D. P. et al. Global patterns and predictors of marine biodiversity across taxa. Nature 466, 1098-1101 (2010).

30. Elith, J. \& Leathwick, J. R. Species distribution models: Ecological explanation and prediction across space and time. Ann. Rev. Ecol. Evol. Syst. 40, 677-697 (2009).

\section{Acknowledgements}

This manuscript is the culmination of a cross-project synthesis between TOPP and the Center for Ocean Solutions' Climate and Predators working group. Financial support for this work was provided by the Sloan Foundation's Census of Marine Life programme, the NF-UBC Nereus programme, the National Research Council and Stanford's Center for Ocean Solutions. TOPP research was funded by the A. P. Sloan, David and Lucille Packard, and Gordon and Betty Moore foundations. Electronic tagging and tracking as part of TOPP was also supported by the Office of Naval Research, NOAA, the E\&P Sound and Marine Life JIP under contract from the OGP, and the Monterey Bay Aquarium Foundation. We thank the TOPP scientific teams and all those who supported animal tagging efforts, particularly our colleagues at IATTC for help with yellowfin tunas, OSU for cetacean tracks, and Grupo Tortuguero and NOAA Southwest Fisheries for turtle and shark research. We thank collaborating TOPP partners and working group leaders for their efforts coordinating, permitting and conducting tagging research during the Census of Marine Life programme. We thank the data management team of TOPP including A. Swithenbank, J. Ganong and M. Castleton in contributing to TOPP data assembly. All animal research was conducted in accordance with appropriate permits (for example, Leatherback turtle Endangered Species Act permit nos. 1159, 1227 and 1596) and IACUC protocols from Stanford University and the University of California. Pacific bluefin tuna work was conducted in Mexican waters with the permission and permits provided by the Mexican Government.

\section{Author contributions}

This climate modelling study was initiated by E.L.H., S.J.B., S.J.J. and R.R.R. The TOPP project was designed and data collection was coordinated by B.A.B., D.P.C. and S.J.B. Tracking data for this project were compiled by S.J.J. and I.D.J., and climate model data were compiled by R.R.R. and J.P.D. Oceanographic data were compiled by E.L.H., S.J.B. and D.G.F. Analyses were conducted by E.L.H., S.J.J., S.J.B. and R.R.R. Figures were created by E.L.H., S.J.B., D.G.F. and S.J.J. The manuscript was written by E.L.H. and edited by S.J.J., R.R.R., S.J.B., D.G.F., I.D.J., S.A.S., L.B.C., J.P.D., D.P.C. and B.A.B.

\section{Additional information}

Supplementary information is available in the online version of the paper. Reprints and permissions information is available online at www.nature.com/reprints. Correspondence and requests for materials should be addressed to E.L.H.

\section{Competing financial interests}

The authors declare no competing financial interests. 